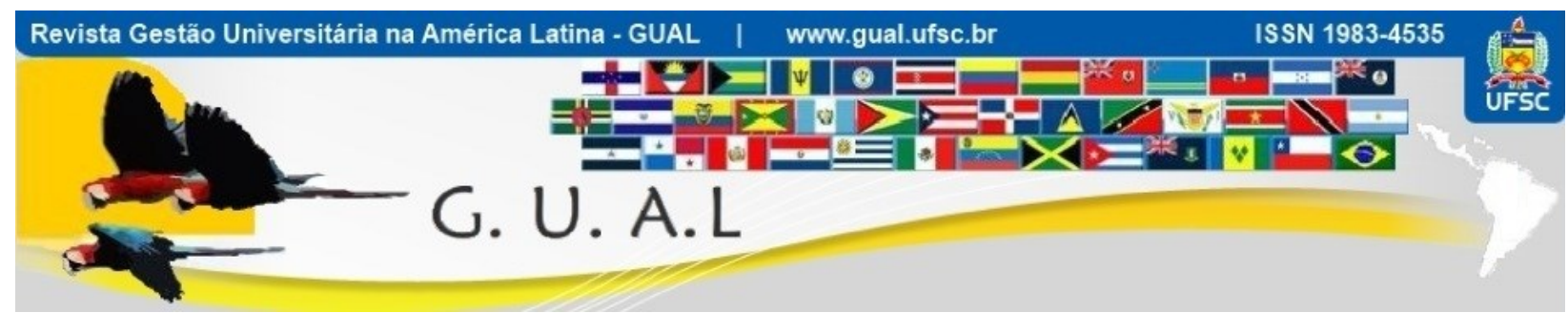

DOI: http://dx.doi.org/10.5007/1983-4535.2018v11n3p211

\title{
RESTAURANTE UNIVERSITÁRIO DA UFPE: UMA ABORDAGEM SISTÊMICA
}

\author{
UNIVERSITY RESTAURANT OF UFPE: A SYSTEMIC APPROACH
}

Carla Ionara Xavier da Silveira Cardoso, Mestre

Universidade Federal de Pernambuco - UFPE carla.ixscardoso@ufpe.br

Danubia Paula da Silva Menezes, Mestre Universidade Federal de Pernambuco - UFPE dannubhya@gmail.com

André Melo de Souza, Mestre Universidade Federal de Pernambuco - UFPE andremeloufpe@gmail.com

Roberta Macedo Baudel, Mestre Universidade Federal de Pernambuco - UFPE betabaudel@hotmail.com

Dinara Leslye Macedo e Silva Calazans, Doutora Universidade Federal do Rio Grande do Norte - UFRN dinaraleslye@yahoo.com.br

Recebido em 24/outubro/2017

Aprovado em 05/agosto/2018

Sistema de Avaliação: Double Blind Review 


\begin{abstract}
RESUMO
Este estudo tem o objetivo de analisar uma situação-problema do restaurante universitário da Universidade Federal de Pernambuco quanto à capacidade limitada do atendimento, à luz da teoria dos sistemas. As situações foram representadas através de arquétipos numa tentativa de maior e melhor compreensão da utilização do pensamento sistêmico diante dos cenários dinâmicos e complexos existentes. Para isso, utilizou-se de pesquisas de opinião realizadas na unidade entre os anos 2011 e 2014, além de documentos da instituição e informações obtidas pelos próprios pesquisadores. Constatou-se que a gestão da unidade não atua de forma sistêmica, apresentando ações paliativas que, em curto prazo, aliviam o sintoma, mas que em seguida, tornam-se precárias. O estudo mostrou que a análise sistêmica a partir da confecção dos arquétipos é uma importante ferramenta que pode ser utilizada no processo decisório. Nesse caso, a atividade de fornecimento de refeição, como atividade-meio de gestão da instituição, é passível de descentralização do fornecimento por meio da ampliação da terceirização dos serviços, como já é a própria unidade; e/ou a realização de convênios com a rede privada já existente no campus mediante contratos com a instituição.
\end{abstract}

Palavras chave: Abordagem Sistêmica. Arquétipos. Restaurante Universitário.

\begin{abstract}
This study aims to analyze a problem situation of the university restaurant of the Federal University of Pernambuco regarding the limited capacity of the service in the light of systems theory. The situations were represented through archetypes in an attempt to better understand the use of systemic thinking in the face of the dynamic and complex scenarios. For that, we used opinion polls conducted at the unit between 2011 and 2014, as well as documents from the institution and information obtained by the researchers themselves. It was found that the management of the unit does not act in a systemic way, presenting palliative actions that, in the short term, alleviate the symptom, but then become precarious. The study showed that the systemic analysis from the construction of the archetypes is an important tool that can be used in the decision making process. In this case, the food supply activity, as an activity-means of management of the institution, is liable to decentralize the supply through the extension of the outsourcing of services, as is the unit itself; and / or the realization of agreements with the private network already existing in the campus through contracts with the institution.
\end{abstract}

Keywords: Systemic Approach. Archetypes. University Restaurant. 


\section{INTRODUÇÃO}

Atualmente, um dos fundamentos utilizados na Gestão Pública é o Pensamento Sistêmico, descrito como o entendimento das relações de interdependência entre os diversos componentes de uma organização, bem como entre a organização e o ambiente externo, com foco na sociedade (FERREIRA, 2009). O pensamento sistêmico pressupõe pensar em etapas e processos, os quais representam o todo, e é por meio desses processos que se configura uma situação ou fenômeno a ser investigado, e a partir daí entender os padrões e características implícitas da organização, a fins de inovar e/ou remodelar uma situação ou problema, além de melhorar a capacidade de aprendizagem.

Fundamentados na teoria sobre o pensamento sistêmico, os arquétipos sistêmicos evidenciam as "estruturas profundas não percebidas à primeira vista" tanto nos eventos quanto nas leituras de várias situações organizacionais. Servem como instrumento para ascensão na ordem de complexidade das percepções de uma situação problema, isto é, é um meio de detecção diagnóstica e de encaminhamento de ações estratégicas (VALENÇA, 2011).

Em outras palavras, capacita a enxergar para além das partes, dos objetos isolados, das hierarquias, do pensamento linear, da estrutura estática e da visão mecanicista; além de ampliar a capacidade de aprender, renovar e inovar continuamente, trazendo à tona as variáveis "escondidas" para tomada de decisões mais assertivas.

Grande parte dos restaurantes universitários (RU’s), que são infraestruturas importantes para as universidades federais, tem como desafio a gestão da capacidade de atendimento, devido ao aumento crescente de demanda em decorrência da adesão ao Programa de Apoio ao Plano de Reestruturação e Expansão das Universidades Federais (REUNI), desde 2007, o qual contempla o aumento da oferta de cursos, a ampliação do número de vagas nos cursos de graduação e entre outras ações, o combate à evasão. Os RU's proporcionam aos alunos e servidores, refeições a um preço acessível sendo um importante mecanismo de inclusão social para estudantes de carência econômica (OLIVEIRA, 2013).

Nessa abordagem dos restaurantes universitários, o uso dos arquétipos sistêmicos constitui um poderoso instrumento ao exercício de planejamento estratégico para tomada de decisão na gestão dos RU's. Frequentemente há proposições de soluções de curto prazo (análise das filas, estudo de layouts etc) em vez de solucionar estruturalmente os graves problemas de maneira a atender a demanda crescente de alunos e servidores sem comprometer o atendimento e a eficiência na prestação dos serviços. Ademais, o que se observa nos RU's, em geral, é a tendência de um comportamento-padrão de estruturas dinâmicas de causalidade referente ao 
aumento constante da demanda que, de acordo com Valença (2011) os arquétipos sistêmicos são “como modelo de 'leituras' ou de 'compreensões' de uma situação que podem ser usadas tanto em casos específicos quanto na generalidade de casos semelhantes".

Assim, o que se pretende com esse trabalho é fazer uma análise a partir da identificação das variáveis críticas e classificação dos eventos diante da construção dos arquétipos sistêmicos e estruturas dinâmicas de causalidade em torno do problema apresentado no Restaurante Universitário da Universidade Federal de Pernambuco (UFPE) referente à gestão da capacidade de atendimento, a fim de compor ferramentas de apoio à tomada de decisão, através da reflexão do funcionamento sistêmico sobre o que é estratégico na situaçãoproblema.

\subsection{CONTEXTUALIZAÇÃO}

O direito fundamental à educação decorre do reconhecimento do dever constitucional do Estado de assegurar a todos o acesso à educação, formando sujeitos capazes de exercer de forma responsável a cidadania. A própria Constituição de 1988, relata a obrigatoriedade de financiamento das universidades públicas alinhadas à igualdade de condições de acesso e permanência na escola. Assim, a assistência estudantil é vista como parte da política educacional essencial à boa formação de cidadãos, ao desenvolvimento e a inclusão social a fim de reduzir as desigualdades e garantir que o aluno tenha condições dignas de finalizar o seu curso, além de contribuir para a democratização das universidades e reforçar seu compromisso social. Apesar do contexto político e econômico desfavorável, as IFES buscam desenvolver ações e manter os serviços de assistência aos estudantes com dificuldades socioeconômicas. Dentre as principais ações e programas estão: programa de moradia estudantil, programa de alimentação, bolsa de transporte, programa de saúde e o apoio à participação em eventos científicos (MAIA, 2008).

Inserido no programa de alimentação, percebe-se a atuação e importância dos Restaurantes Universitários (RU) que tem como principal missão produzir e fornecer refeições de qualidade higiênico-sanitária e nutricional satisfatória a um custo reduzido e/ou sem custo para os estudantes com vulnerabilidade socioeconômica. No entanto, o programa de Reestruturação e Expansão das Universidades Federais - REUNI - criado em 2007 com o objetivo de ampliar o acesso e permanência de alunos na educação superior vem transformando a gestão do RU num desafio. 
Essa nova realidade que envolve o cenário de apoio à Reestruturação e Expansão e a democratização do ensino, dentre outros pontos, enfoca a ampliação da oferta de vagas, a permanência desses estudantes para evitar a evasão e o aumento e fortalecimento dos programas de assistência estudantil. Desde a implantação REUNI, instituído pelo Governo Federal, em 2007, por meio do Decreto n 6.096 de 24 de Abril de 2007, o número de alunos e servidores nas universidades federais aumentou gradualmente, sobrecarregando, consequentemente a demanda dos restaurantes universitários.

Em contrapartida, percebe-se que as Universidades Públicas não foram preparadas para atender a demanda decorrente das políticas de inclusão, gerando com isso limitações de atendimento centradas, principalmente, na falta de estrutura física, econômica e de pessoal, ensejando a insatisfação do usuário (MAIA, 2008; MARQUES, PEREIRA e ALVES, 2010; OLIVEIRA, 2013).

O Restaurante Universitário da UFPE foi reinaugurado em 28 de fevereiro de 2011 e está vinculado a Pró-Reitoria de Assuntos Estudantis (PROAES). É administrado por empresa terceirizada, segundo o Contrato $\mathrm{n}^{\circ} 32 / 2014 /$ UFPE e funciona atualmente numa área construída por $1.292 \mathrm{~m} 2$. O horário de funcionamento é das $07 \mathrm{~h}$ às $08 \mathrm{~h}$ (desjejum), das $10 \mathrm{~h} 30 \mathrm{~min}$ às $14 \mathrm{~h} 30 \mathrm{~min}$ (almoço) e das $17 \mathrm{~h}$ às $19 \mathrm{~h}$ (jantar). Tem capacidade física para 550 pessoas sentadas e capacidade de produção de 10.500 refeições/dia (500 desjejuns, 5.000 almoços e 5.000 jantares). De acordo com o sistema Siga/RU-UFPE, atualmente o atendimento diário é em média de 4.420 refeições/dia (220 desjejuns para alunos com subsídio integral; 2.800 almoços e 1.400 jantares). Conforme o Contrato n³2/2014/UFPE devem ser servidos até 500 desjejuns, até 3.000 almoços e até 1.500 jantares. Não obstante, constata-se que as 3.000 refeições previstas para o almoço, por exemplo, não são atingidas, provavelmente devido à fila para o atendimento, pois mesmo durante o horário de pico, 11:00h às 13:00h, não faltam lugares para sentar no refeitório.

O campus Recife- possui 33.342 alunos de graduação e pós-graduação (dados de junho/2015. Fonte: PROACAD/UFPE- Pró-Reitoria para Assuntos Acadêmicos). Já em relação ao cadastro no sistema do RU (Siga/RU), em junho de 2015, o número de cadastrados era 21.873, sendo subsídio parcial: 18.464 , isto é que pagam $\mathrm{R} \$ 3,00$ pela refeição e subsídio total: 3.409, que são isentos do pagamento. Daí percebe-se que o RU atende aproximadamente $9,0 \%$ da demanda de estudantes, sem contabilizar os servidores (técnicos administrativos e docentes). 
O problema da capacidade limitada do atendimento do RU é evidenciado, principalmente durante o almoço, onde se todos os estudantes que possuem cadastro com subsídio total fossem fazer a refeição, não seriam atendidos, pois são servidos, no máximo, 3.000 refeições. Além da concentração de boa parte dos usuários precisarem utilizar o RU entre 11:00h e 12:00h (32,4\% segundo pesquisa de opinião realizada pelo Restaurante Universitário- outubro/ 2014). Essa pesquisa também destaca que 44,7\% dos respondentes frequentam o RU menos de três vezes na semana devido as grandes filas, corroborando o problema em questão.

\section{REFERENCIAL TEÓRICO}

\subsection{TEORIA GERAL DE SISTEMAS E A ABORDAGEM SISTÊMICA}

O contexto mundial do pós-guerra e as consequentes mudanças comportamentais e tecnológicas impulsionaram dinâmicas sociais e econômicas que marcariam os anos posteriores despertando a atenção de variadas ciências dentre elas as sociais e as de informação. O propósito era explicar as dinâmicas dos sistemas existentes o que envolvia tarefas com variados níveis de complexidade. Assim, entre as décadas de 50 e 60, sugiu a Teoria Geral dos Sistemas, também conhecida como TGA, a partir dos estudos desenvolvidos por Ludwing Von Bertalanffy. Seus resultados apontaram para dinâmicas que se assemelham às leis que governam os sistemas e subsistemas biológicos (BERTALANFFY, 1977). Essa abordagem sistêmica lançou mão de princípio holístico cujo pressuposto é que o todo é maior do que a simples soma das suas partes assim como outros pressupostos são contemporaneamente admitidos na composição da abordagem sistêmica (MORIN, 1977 apud LEITE, 2004).

Os reflexos mundiais do pós-guerra e as consequentes mudanças comportamentais e tecnológicas impulsionaram dinâmicas sociais e econômicas que marcariam os anos posteriores, razões estas que despertaram a atenção de variadas ciências dentre elas as sociais e as de informação. Assim foram iniciadas pesquisas que buscavam explicar as dinâmicas dos sistemas e subsistemas com abordagem macro o que envolvia tarefas com alto nível de complexidade.

Segundo Silva (2008), um sistema pode ser definido "como um conjunto de elementos integrantes e interdependentes relacionados cada um ao seu ambiente de modo a formar um todo organizado". Nessa concepção, tem-se que uma organização ao adotar a perspectiva de 
uma abordagem de sistema para analisar suas situações, busca verificar não apenas os elementos, mas também as interações existentes.

A Teoria Geral de Sistemas é vista como genérica por se tratar de uma forma de pensar cuja aplicação tem grande alcance geral, embora existam limitações. Apresenta relevante utilidade na fundamentação de teorias, pois "a dimensão sistêmica organizacional deve estar presente em todas as teorias" (MORIN, 2005).

Utilizando essa retórica, Jay Forrester, enquanto trabalhava na escola de administração do MIT (Massachusets Institute of Technology) desenvolveu a disciplina denominada dinâmica de sistemas, e em conjunto com John F. Collins criou dois modelos de estudos estratégicos urbanos e mundiais: "Urban Dynamics" (Dinâmica Urbana) e "World Dynamics" (Dinâmica Mundial). A dinâmica de sistemas se ocupa com a identificação de características básicas de qualquer sistema, quais sejam: relações de causa e efeito, tempos de resposta e efeitos de realimentação (VILLELA, 2005).

Essa abordagem sistêmica possibilita identificar uma diversidade de problemas e situações cuja complexidade está relacionada à quantidade de causas e variáveis envolvidas; e tem o propósito de representar as relações de interdependência de variáveis em determinada dinâmica, lançando mão de modelos de representação de eventos que auxiliem no processo de análise e decisão.

Nesse sentido, os modelos oriundos do paradigma da TGA auxiliam na compreensão de determinados eventos e seus ciclos permitindo aos gestores posicionamentos com alto grau de objetividade e respaldo científico. Alinhado a essa temática, Senge (1990), em sua obra $A$ quinta disciplina, destaca a importância do pensamento sistêmico no processo de aprendizagem das organizações e o conceitua como "uma disciplina para ver o todo". O autor revela que para o entendimento dos fenômenos e realidades complexas, deve-se criar modelos diagnósticos e normativos. Em sua discussão utiliza arquétipos sistêmicos como instrumentos de descrição e diagnóstico de situações de gestão organizacional.

\subsection{ARQUÉTIPOS SISTÊMICOS}

A palavra Arquétipo vem do grego archetypos, que significa "primeiro da sua espécie", e se refere a algo arcaico, profundo, enraizado, estrutural, tácito. O termo "arquétipo" vem sendo usado em várias áreas do conhecimento e serve a diferentes teorias (VALENÇA, 2011). O autor afirma que o uso dos arquétipos, faz surgir leituras da realidade distintas das convencionais com as quais as pessoas estão condicionadas a fazer, perceber, raciocinar e agir 
sobre a realidade. Eles servem pra entender e dominar os próprios modelos mentais, ou seja, se apropriar das representações da realidade, das leituras de "como funcionam". Quando aplicados às percepções e às análises das situações nas organizações, se apresentam em forma de padrões de interligações causais.

No âmbito científico, os arquétipos se propõem a classificar as estruturas do sistema e seus comportamentos, em especial os contraintuitivos que envolvem maior complexidade (WOLSTENHOLME, 2003). Aplicados a questões de modelagem mental, valores de prática e aprendizagem social, eles ajudam na percepção das estruturas dinâmicas de causalidade criadas pelos padrões comportamentais, isto é, distingue uma causalidade da outra, nos diferentes contextos (VALENÇA, 2011).

De acordo com Valença (2011), a principal função dos arquétipos sistêmicos é esclarecer e articular as inter-relações das variáveis (elementos governantes) como cadeias circulares de causa e efeito, com o objetivo de entender os processos circulares de mudança. E ainda, permite a identificação de pontos estratégicos que produzem melhorias significativas e duradouras, ou seja, os pontos de alavancagem.

$\mathrm{Na}$ prática da gestão, os arquétipos são modelos destinados a servir ao gestor na identificação e análise de possíveis cenários de interação organizacional. O gestor partindo da observação inicial das variáveis organizacionais e da dinâmica entre elas pode fazer uso de seu modelo mental acerca da dinâmica de arquétipos sistêmicos e, assim, definir suas ações (SORDI, NELSON, BIANCHI, 2014).

É importante destacar, que anterior à construção dos arquétipos, há o uso da técnica do mapa causal. A técnica de análise causal é uma forma de apresentar e apreciar os fundamentos da teoria geral de sistemas pelos administradores. Serve para compreender melhor como pensar sistemicamente, de acordo com um conjunto de passos que permite o entendimento de uma situação de transformação organizacional: 1.Definir uma situação complexa de interesse; 2.Apresentar história por meio de eventos; 3.Identificar variáveis-chave; 4.Traçar padrões de comportamento; 5.Desenhar o mapa sistêmico; 6.Identificar modelos mentais; 7.Realizar cenários; 8.Modelar em arquétipos (PRETO, FIGUEIREDO, 2012).

Atualmente, os pesquisadores identificaram uma dúzia de arquétipos de sistema (SENGE, 2005), que às vezes, diferem em nomenclaturas, porém todos levam em consideração os mesmos princípios: ciclos de reforço, balanceamento e retardos. Os ciclos de reforço possuem um comportamento de expansão, em que o efeito de uma variável sobre outra e sobre si mesma é no mesmo sentido (feedback positivo), enquanto nos ciclos de 
balanceamento, o efeito resultante é no sentido oposto (feedback negativo). Já o retardo, é o tempo entre o efeito de uma variável sobre outra.

Nessa pesquisa serão abordados alguns dos modelos propostos para as organizações descritos por Senge (2005) e Valença (2011). Senge (2005) parte de duas perguntas: é uma situação de crescimento? ou é uma situação problemática? Dependendo da resposta os seguintes modelos arquétipos são desmembrados: Processo de equilíbrio com defasagem; Limites ao crescimento; Transferência de responsabilidade; Metas declinantes; Escalada; Sucesso para os bem-sucedidos; Tragédia dos comuns; Consertos que estragam; Crescimento e subinvestimento. Cada qual caracterizando um padrão de comportamento em resposta a um feedback e evidenciando uma situação-problema específico.

Valença (2011) faz uma derivação com cinco categorias de situações arquetípicas a partir da árvore de arquétipos transcrita por Senge (2005): 1.situações de crescimento que sofrem algum impedimento; 2.situações de colaboração ou parceria que não estão em sinergia; 3.situações de prejuízo por concorrência acirrada; 4.situações de desvio de missão, objetivos ou metas que levam a postergação ou a acomodação; e 5.situações de desculpas, transferência de responsabilidade ou rotinas defensivas. Destas derivam um elenco de 11 tipos de arquétipos; 1. Limite ao crescimento; 2. Princípio da atratividade; 3.Crescimento com subinvestimento; 4. Sucesso para os bem-sucedidos; 5. Adversários acidentais; 6. Escalada; 7. Tragédia do fator comum; 8. Deriva de metas; 9. Crescimento com subinvestimento por deriva de metas; 10. Solução quebra-galho e 11. Transferência de responsabilidade.

Cada arquétipo integra um determinado contexto, ambiente, relações, processos, fluxos e limites, e de acordo com a sua teoria, constroem o diagnóstico da situação. Trata-se de visualizar sistematicamente as situações de forma a manter o foco nas variáveis mais pertinentes a uma situação complexa. Sua finalidade é responder, o que é de fato, importante, urgente e impactante.

Nesse sentido, o resultado prático dos arquétipos é levar os envolvidos a pensar nas estratégias de ação, direcionados sempre, para a atuação nos pontos de alavancagem, que são as ações ideais- apreciativas, onde as mudanças nas estruturas podem levar a avanços significativos e duradouros. O ponto de alavancagem é indicado pela teoria correspondente ao arquétipo e segue o princípio da economia dos meios, "os melhores resultados provêm não de esforços em larga escala, mas sim de pequenas ações bem focalizadas” (SENGE, 2005). Leva a organização refletir e decidir sobre o que é estratégico na situação para resolver o problema de maneira sistêmica. 


\section{ESTRATÉGIAS METODOLÓGICAS}

O método de análise do comportamento dinâmico de um sistema tem início ao se identificar o problema a ser resolvido ou o comportamento que precisa correção. A partir da identificação das estruturas de ciclos de realimentação pode-se determinar como as mudanças nos processos decisórios interferem no comportamento dinâmico do sistema (ACCIOLY, FIGUEIREDO, 2010).

No sistema dinâmico estão organizadas as variáveis que compõem um ciclo de relação de causa-efeito (ciclos de alimentação). A elaboração e construção de diagramas de loops causais são realizadas com a finalidade de compreender a estrutura geral do sistema (visão do todo). Faz-se um mapeamento das interações das variáveis, mostrando a influência de umas sobre as outras.

O diagrama de loop causal é uma representação gráfica que permite visualizar as interrelações dinâmicas entre as variáveis e testar hipótese sobre o problema. Os diagramas causais são definidos como sistemas formados por fluxos de realimentação e são compostos por loops de reforço e loops de equilíbrio, por relações de causa e efeito entre as variáveis e por defasagens de tempo (delays) entre causa e o efeito, que podem ser representados por barras paralelas. O loop (palavra inglesa que sugere circularidade) acontece quando existe entre as variáveis um impacto causal recíproco, ou seja, uma exerce influência direta sobre a outra. (DE SORDI, NELSON, BIANCHI, 2014)

Os loops de reforço são aqueles que ampliam os efeitos de uma variável sobre a outra, sendo representados pela letra "R" (reforço). Os loops de equilíbrio, por sua vez, são aqueles que estabilizam o sistema, anulando o efeito de uma variável sobre a outra, buscando trazer equilíbrio ao sistema, sendo representados pela letra"B" (balanceamento).

O que define o caráter de reforço ou equilíbrio de um loop é a quantidade de relações existentes. Se existem ligações negativas em número par o loop é de reforço. Se houver ligações negativas em número ímpar, o loop é de equilíbrio. No diagrama, o fluxo de causalidade é representado pelas setas que indicam se duas variáveis possuem relação de mesma direção ou relações opostas (SILVA, LOURENZANI, 2011).

A técnica de mapa causal foi desenvolvida para atuar como um meio de esmiuçar problemas complexos e especificar os conceitos referentes aos arquétipos sistêmicos da teoria geral de sistemas. "O algoritmo da técnica empregada - mapa causal - é fundamentado em 
arquétipos sistêmicos de amplificação de desvios, limitação de desvios e loops de amplificação" (DE SORDI, NELSON, BIANCHI, 2014, p.341).

Para o processo de diagramação foram seguidos os seguintes passos: 1. Selecionado um problema e identificadas as causas associadas; 2.Identificadas as variáveis-chave; 3.Identificados os relacionamentos entre as variáveis (Matriz de causalidade); 4.Categorizaram-se as variáveis sobredeterminantes, as de segunda ordem e as de consequência; 5.Foram mapeados os elos causais entre variáveis-chave, identificando as relações mais significativas (mapa causal); 6.Identificados os enlaces reforçadores e equilibradores de realimentação no mapa; 7.Formuladas as hipóteses relacionando a estrutura do mapa à dinâmica do problema identificado.

Por fim, para o processo de modelagem do sistema foi utilizado o software VENSIM PLE® - Personal Learning Environment, da Ventana Systems em sua versão 6.3, disponibilizada através da Internet, no site www.vensim.com, sendo uma plataforma gratuita para fins acadêmicos e educacionais, criado para modelar, resolver e analisar sistemas que utilizem a metodologia da dinâmica de sistemas.

\subsection{PROCESSO DE DIAGRAMAÇÃO}

\subsubsection{Variáveis}

A partir da problemática descrita na introdução desse trabalho e por meio de fonte de dados secundários resultantes de pesquisas de opinião realizadas na unidade entre os anos de 2011 a 2014, de documentos da instituição e de informações obtidas pelos próprios pesquisadores foi possível identificar e elencar as seguintes variáveis que foram posteriormente categorizadas: Tamanho da fila; Capacidade de atendimento; Procura pelo serviço; Investimento na unidade atual (infraestrutura/materiais/equipamentos); Criação de novas unidades/ descentralização; Satisfação do usuário; Recursos UFPE (alocação); Ampliação do espaço físico; Desempenho do RU.

Além dessas, foi possível identificar outras variáveis relacionadas ao modelo de gestão como: gestão centralizada, recorrência de problemas, gestão participativa, necessidade de contribuições inovadoras e percepção limitada do problema. No entanto, não serão categorizadas nesse estudo por se apresentarem em campo mais amplo do sistema. O enfoque do estudo encontra-se, portanto, em analisar um subsistema desse sistema. 


\subsubsection{Matriz de Causalidade}

Sua construção foi realizada colocando-se todas as variáveis causais nas linhas que correspondem à numeração colocada nas colunas que representam essas mesmas variáveis, identificando-se o relacionamento entre os pares de variáveis (Linha-coluna). Para os relacionamentos positivos coloca-se "cm" (para as relações de mesma direção) e para os negativos "co" (para relação de direção oposta). Como exemplo, podemos destacar na matriz as variáveis 1 - Tamanho da fila e 2 - Capacidade de atendimento e fazer a seguinte pergunta: “O'Tamanho da fila' influencia positivamente, negativamente ou mantem inalterada a 'Capacidade de atendimento'? Se influencia positivamente coloca-se $\mathbf{c m}$, se influencia negativamente coloca co e, se mantém inalterada deixa-se o espaço em branco.

Sucessivamente, foram realizadas as análises cruzadas até o preenchimento de toda a matriz. Para cada variável foi feito o somatório do quanto ela influencia (somatório da linha) e o quanto é influenciada (somatório da coluna).

Figura 1 Matriz de Causalidade

\begin{tabular}{|c|c|c|c|c|c|c|c|c|c|c|c|}
\hline VARIÁVEIS & 1 & 2 & 3 & 4 & 5 & 6 & 7 & 8 & 9 & SC & SE \\
\hline 1. Tamanho da fila & & co & - & - & - & co & - & - & co & 3 & 3 \\
\hline 2. Capacidade de atendimento & co & & & - & _ & $\mathrm{cm}$ & - & - & $\mathrm{cm}$ & 3 & 4 \\
\hline 3. Procura pelo serviço & cm & _ & & - & _- & - & _ & - & _ & 1 & 4 \\
\hline $\begin{array}{l}\text { 4. Investimento na unidade atual } \\
\text { (infraestrutura/materiais/equipamentos) }\end{array}$ & - & cm & - & & - & - & - & cm & - & 2 & 1 \\
\hline $\begin{array}{l}\text { 5. Criação de novas unidades/ } \\
\text { descentralização }\end{array}$ & - & $\mathrm{cm}$ & - & - & & - & - & $\mathbf{c m}$ & - & 2 & 1 \\
\hline 6. Satisfação do usuário & - & - & $\mathbf{c m}$ & - & - & & - & - & - & 1 & 4 \\
\hline 7. Recursos UFPE (alocação) & - & - & - & $\mathbf{c m}$ & cm & - & & - & - & 2 & 0 \\
\hline 8. Ampliação do espaço físico & - & cm & - & - & - & - & - & & - & 1 & 2 \\
\hline 9. Desempenho do RU & co & - & - & - & - & $\mathbf{c m}$ & - & - & & 2 & 2 \\
\hline SE & 3 & 4 & 4 & 1 & 1 & 4 & 0 & 2 & 2 & & \\
\hline
\end{tabular}

$\mathrm{Cm}=$ Causa no mesmo sentido

$\mathrm{Co}=$ Causa no sentido oposto

$\mathrm{SC}=$ Soma das causas

$\mathrm{SE}=$ Soma dos Efeitos 


\subsubsection{Diagrama de Sobredeterminância}

A partir das informações obtidas na matriz de causalidade foi construído o Diagrama de sobredeterminância de causalidade, onde as variáveis de maior somatório foram classificadas como sobredeterminantes, as de somatório intermediário como variáveis de segunda ordem e as de menor somatório como variáveis de consequência. A realização desse diagrama permite a identificação do quanto cada variável influencia ou é influenciada tanto de forma negativa, como de forma positiva.

Como esclarecimento podemos tomar a variável 'tamanho da fila'. A mesma influencia três (3) variáveis e é influenciada por três (3). Isso significa que uma melhora ou piora do tamanho da fila vai interferir na capacidade de atendimento, na satisfação do usuário e no desempenho do RU; e que a capacidade de atendimento, a procura pelo serviço e o desempenho do RU interferem no tamanho da fila. Percebe-se ainda que existem influencias mútuas entre as variáveis, o que caracteriza os loops de causalidade.

Figura 2 Diagrama de Sobredeterminância

\begin{tabular}{llll}
\hline & Variáveis & & \\
\hline Capacidade de atendimento & 34 & sobredeterminante \\
Tamanho da fila & 33 & sobredeterminante \\
\hline $\begin{array}{l}\text { Desempenho do RU } \\
\text { Criação de novas unidades/ descentralização } \\
\begin{array}{l}\text { Investimento na unidade } \\
\text { (infraestrutura/materiais/equipamentos) }\end{array}\end{array}$ & 22 segunda ordem \\
Recursos UFPE (alocação) & atual & 21 segunda ordem \\
\hline Procura pelo serviço & 20 segunda ordem \\
Satisfação do usuário & 14 consequência \\
Ampliação do espaço físico & 14 consequência \\
\hline
\end{tabular}

\subsubsection{Mapa Causal (Diagrama Loop de Causalidade)}

O mapa causal é uma técnica que permite a compreensão de problemas complexos permitindo a representação sistêmica de cenários típicos das organizações proporcionando aos gestores um maior discernimento nas tomadas de decisões através da construção e análise de arquétipos sistêmicos. 
Figura 3 Diagrama de loop causal para o Restaurante Universitário da UFPE

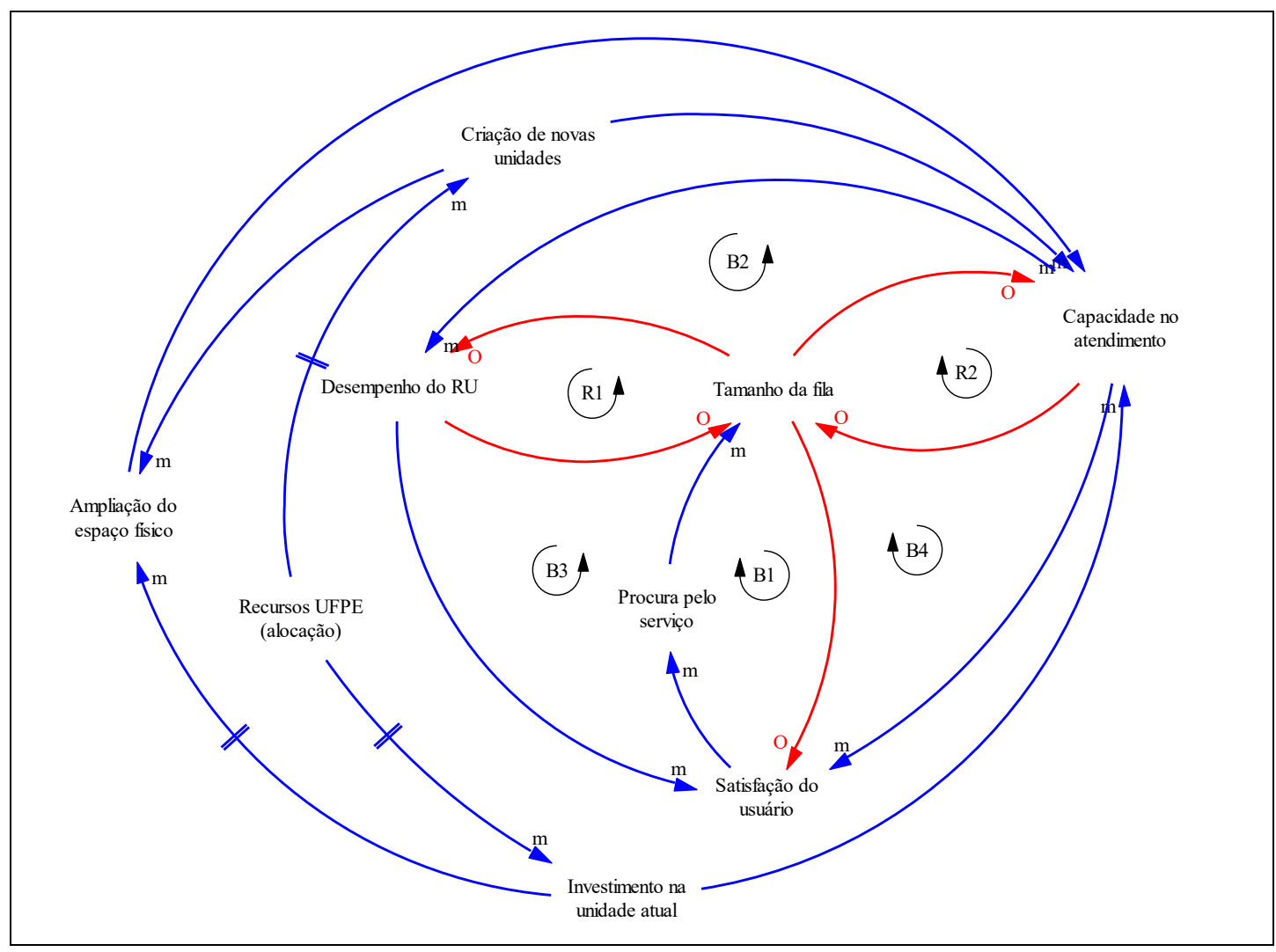

O diagrama da figura 3 foi estruturado com a finalidade de analisar as principais relações de influências entre as variáveis, onde se destacam seis ciclos de realimentação, sendo dois de reforço e quatro de balanceamento. Em R1, um aumento no tamanho da fila acarreta diminuição do desempenho do RU que, por sua vez, reforça o aumento no tamanho da fila. Em R2 o aumento do tamanho da fila implica em diminuição da capacidade de atendimento do RU que consequentemente acarreta o aumento da fila. Em B1, caso ocorra uma maior procura pelo serviço haverá um aumento no tamanho da fila o que diminuirá a satisfação do usuário, acarretando a diminuição pela procura do serviço. Em B2, uma melhora no desempenho do RU aumenta a satisfação do usuário que procura mais o serviço. Contudo, essa maior procura aumenta o tamanho da fila, o que implica na diminuição do desempenho do RU. Em B3, a maior procura pelo serviço aumenta o tamanho da fila diminuindo a capacidade no atendimento e consequente queda no desempenho do RU, o que gera diminuição da satisfação do usuário que reduz sua procura pelo serviço. Em B4, a melhora da capacidade no atendimento aumenta a satisfação do usuário que procura mais pelo serviço acarretando aumento da fila e consequente diminuição da capacidade de atendimento. 


\section{ANÁLISE DOS ARQUÉTIPOS}

$\mathrm{Na}$ perspectiva sistêmica, tomando a situação-problema do RU (capacidade de atendimento limitada), foram identificadas 04 situações que exibem: situação de desvio de objetivos ou metas que levam a postergação; situação de colaboração que não está produzindo sinergia; situação de crescimento; e situação de fuga ou transferência de responsabilidade. Sendo refletidas nos seguintes arquétipos: consertos que estragam; sucesso para os bemsucedidos; crescimento e subinvestimento; e transferência de responsabilidade. Abaixo serão explicados conceitualmente e analisados.

Vale ressaltar que o tipo de arquétipo deve estar alinhado ao problema e ao contexto a fim de explicitar a interação mútua entre as suas partes, e principalmente as inter-relações entre elas e não acometer o ponto de alavancagem. Diante disso, não foi identificada nesse estudo a situação de prejuízo por concorrência acirrada/ competitividade (arquétipo modelo escalada), pois a Instituição prioriza nas ações referentes ao RU o atendimento nutricional a todos os estudantes, não levando em consideração, por exemplo, a política comercial: venda da refeição, preço ou concorrência; existe aqui a função social implícita, através do subsídio financeiro.

\subsection{ARQUÉTIPO 1- CONSERTOS QUE ESTRAGAM}

Esse tipo de arquétipo remete a presença de problemas crônicos que retardam o crescimento e prejudicam o alcance de melhores desempenhos e trata os problemas com soluções de caráter temporário que não resolvem o problema por completo. Na maioria das vezes, costuma agravar a situação, devido às consequências não intencionais associadas ao "quebra-galho". É o que mostra a figura 4 com dois ciclos de realimentação, sendo um de balanceamento (B) e outro de reforço (R).

Há um problema urgente que é a insatisfação do usuário principalmente com o tamanho da fila e, para tentar solucioná-lo utiliza-se a tática do investimento na unidade atual, por exemplo: acréscimo do número de catracas para agilizar a entrada no refeitório; mudanças no sistema das catracas para ser mais rápida a identificação biométrica; colocação de toldos na parte externa para gerar um melhor conforto durante a espera nas filas; alteração do layout no refeitório; acréscimo do número de balcões para distribuição das refeições; acréscimo do número de mesas e cadeiras etc. 
Figura 4 Arquétipo: Consertos que estragam

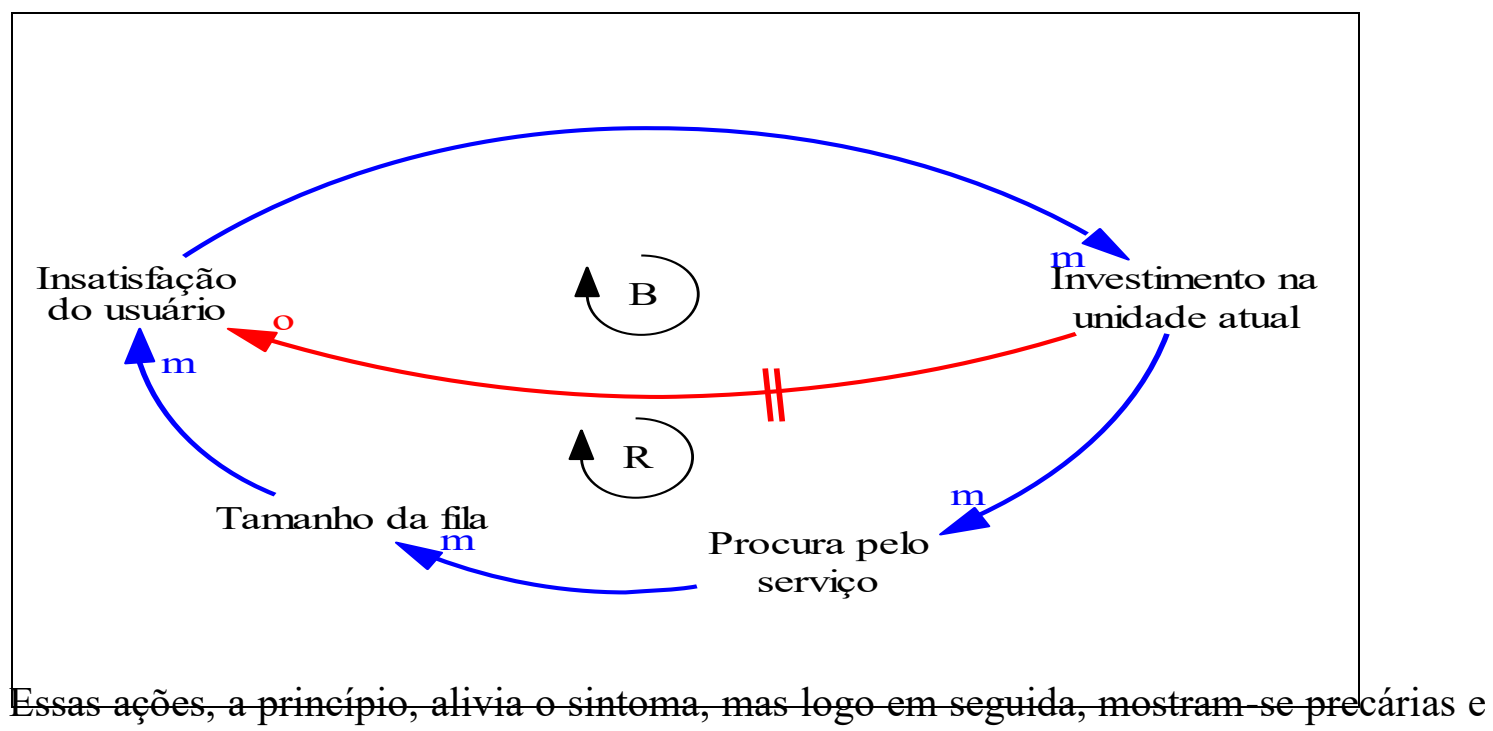

acabam gerando um agravamento da situação, uma vez que a melhora no primeiro momento atrai mais usuários, aumentando com isso a demanda e o tamanho da fila, consequentemente, a insatisfação do usuário.

Para alavancar a solução deve-se manter o foco a longo prazo. Na medida do possível utilizar as soluções de curto prazo somente enquanto trabalha em uma solução a longo prazo. Nesse caso, enquanto há o investimento na unidade atual do RU, os gestores devem estar atentos na consequência dessa ação, que é o aumento da demanda com consequente impacto na qualidade do atendimento, e devem estar dispostos a investir novamente na unidade como também em novas unidades. É necessário, também, oferecer alternativas de fornecimento de alimentação que não seja somente a unidade atual do RU, como por exemplo, a concessão de auxílio alimentação aos estudantes para que possam fazer uso de restaurantes em torno do campus.

\subsection{ARQUÉTIPO 2 - SUCESSO PARA OS BEM-SUCEDIDOS}

$\mathrm{Na}$ situação de sucesso para os bem-sucedidos, ocorre a destinação diferenciada de recursos que proporcionam desempenhos divergentes. De acordo com Senge (2014), há uma competição por apoio ou por recursos limitados entre duas atividades, grupos ou indivíduos no qual o que se tornar mais sucedido ganhará mais apoio e com isso deixa o outro em desvantagem. Percebe-se, com isso, que esse comportamento competitivo é pouco saudável, uma vez que o ideal seria uma conquista equilibrada entre as duas situações. 
Figura 5 Arquétipo: Sucesso para os bem-sucedidos

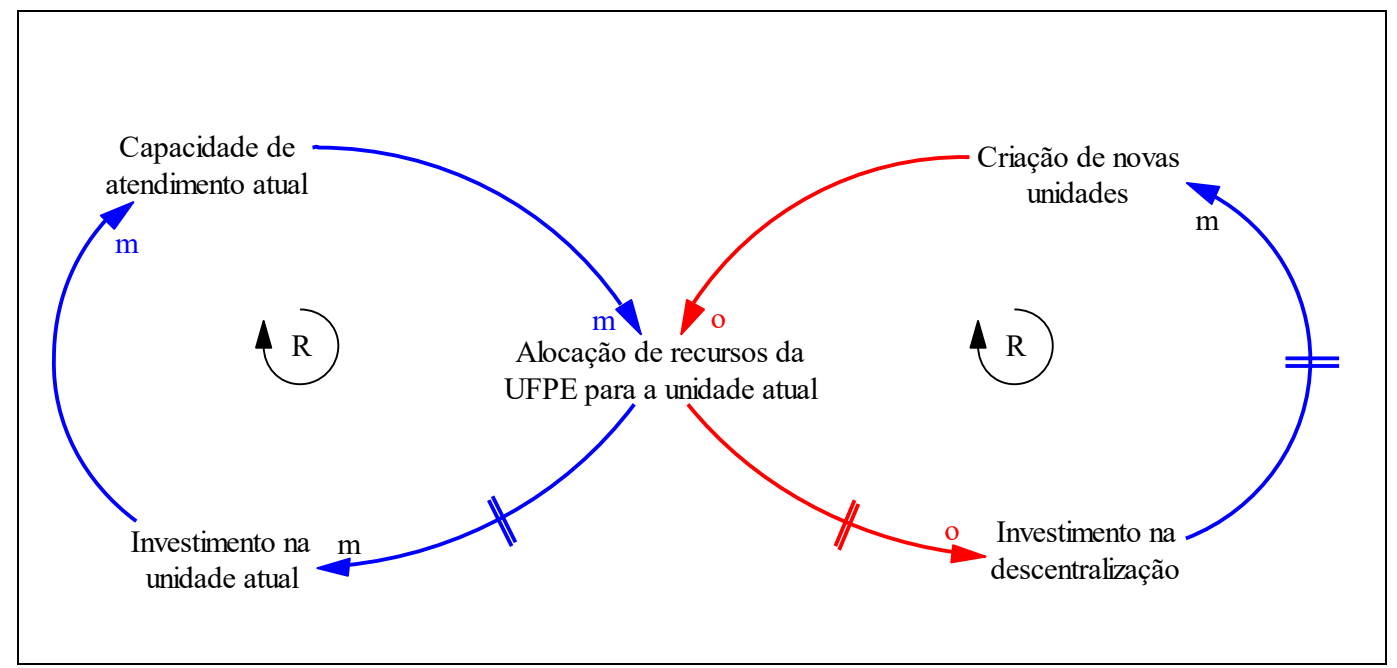

Percebe-se que um dos lados é beneficiado com mais recursos e recompensas (bemsucedido), nesse caso, o investimento na unidade atual, quando, por exemplo, são comprados mais balcões de distribuição das refeições. Porém, em virtude dos recursos serem escassos o sistema é forçado a limitar os recursos destinados à descentralização das unidades (malsucedido). Preso a esse sistema, deixa de envidar esforço no que realmente seria mais proveitoso e bem avaliado. De acordo com Valença (2011) "Essa dinâmica é influenciada por diversos fatores internos e externos, que levam o sistema a acreditar no desempenho somente dos bem-sucedidos, como merecedor de mais investimentos".

Numa visão gerencial, o objetivo é desenvolver ações que busquem equilibrar a situação para enfraquecer a concorrência pelo recurso limitado e para isso é preciso repensar o sucesso em apenas uma das situações, uma vez que a ideia é a de cooperação mútua.

\subsection{ARQUÉTIPO 3 - CRESCIMENTO E SUBINVESTIMENTO}

Este tipo de arquétipo traz a ideia de que há um momento de crescimento e uma latente necessidade de investimento para aumentar a capacidade da situação. Busca o entendimento das situações onde existem iniciativas que levam ao crescimento e, como a falta de investimento podem inviabilizá-lo. Se o ciclo é favorável (crescimento) torna-se necessário que outros aspectos do sistema tenham também melhor desempenho. Contudo, alguns pontos do sistema começam a não ter mais capacidade de responder a esse crescimento (atendimento, infraestrutura, etc). Essa defasagem reflete que existe uma deficiência, uma falta de investimento. A falta de percepção da necessidade de investir leva os gestores a atribuírem outros motivos para a diminuição do desempenho. Assim, o gestor só irá perceber o 
decrescimento a partir do momento que o problema se propaga. Isso acontece em decorrência de certa acomodação devido à melhora momentânea do desempenho por conta das soluções paliativas, havendo um subinvestimento que poderá acarretar em colapso do sistema (CARVALHO, 2010).

Figura 6 Arquétipo: crescimento e subinvestimento

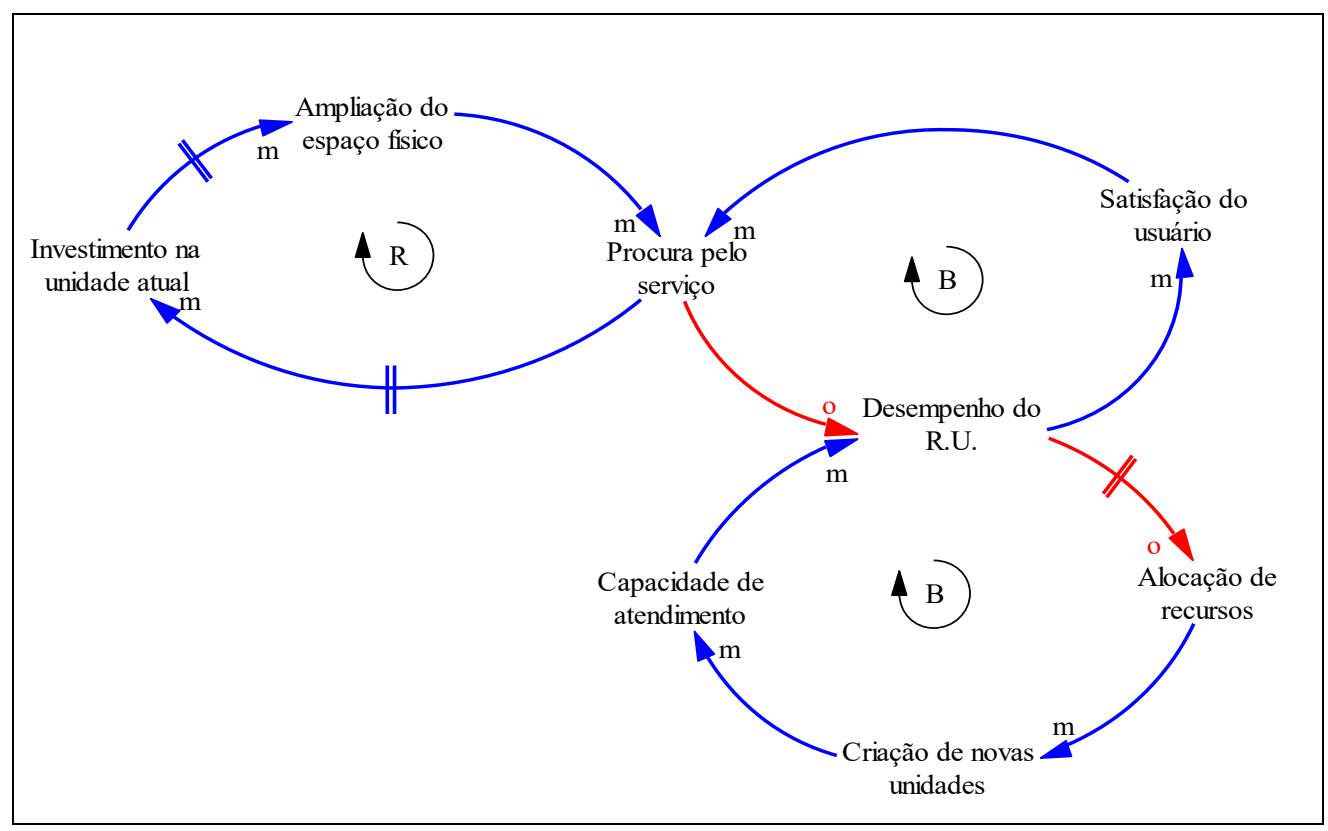

O diagrama da figura 6 apresenta-se com três ciclos de realimentação, sendo dois de balanceamento (B) e um de reforço $(\mathrm{R})$ com tempo de retardo na destinação dos recursos tanto para a ampliação do espaço físico atual quanto para a criação de novas unidades. Percebe-se nesse arquétipo que existe, em decorrência da procura maior pelo serviço, um investimento na unidade atual que vai proporcionar uma ampliação do espaço físico existente, o que acarretará numa maior procura dos usuários. Essa procura implica num aumento de demanda, onde o RU começa a não responder ao crescimento, havendo uma diminuição do seu desempenho que gerará uma insatisfação do usuário. A partir disso, haverá um decréscimo da procura e, numa situação de acomodação, a gestão do RU deixa de investir como antes (subinvestimento). Isso gera menor alocação ou ausência de recursos para a futura criação de novas unidades, havendo um decréscimo na capacidade de atendimento, gerando diminuição no desempenho do RU e, novamente, mais insatisfação dos usuários.

Percebe-se que o arquétipo aponta para uma solução ao se atuar no balanceamento inferior. Contudo, uma reação tardia provoca um comportamento de "bola de neve" e o fato 
de não se antecipar aos fenômenos gera uma ausência de precaução diante do contexto atual, onde existe uma grande ameaça para alocação de recursos devido a sua escassez.

Nesta dinâmica uma alavancagem na alocação dos recursos financeiros e materiais para ampliar o número de unidades do RU do campus universitário da UFPE resultará em aumento da capacidade de atendimento, melhoria do desempenho, da satisfação do usuário fortalecendo os balanceamentos (B). Esses balanceamentos, por sua vez, influenciarão no reforço $(\mathrm{R})$ permitindo atender o aumento da procura pelo serviço de alimentação apoiando, continuamente e efetivamente, a política de retenção da evasão estudantil.

É necessário, portanto, fazer-se previsões sobre as capacidades e infraestruturas que serão necessárias além da capacidade atual. Segundo Senge (2014), sub-investimento significa desenvolver menos capacidade do que é realmente necessário para atender à crescente demanda dos clientes.

\subsection{ARQUÉTIPO: TRANSFERÊNCIA DE RESPONSABILIDADE}

A dinâmica central desse arquétipo está na exposição dos problemas crônicos, que impedem o crescimento e consequentemente o alcance de melhores desempenhos. Teoricamente a solução fundamental desprende mais tempo, pessoal, dinheiro etc., então são realizadas as soluções sintomáticas, com ações pontuais que apresentam uma recuperação limitada, e com o tempo há o retorno dos problemas e aparecimento de consequências indesejadas ou efeito colateral, os quais prejudicam ainda mais as possíveis soluções futuras e mais acertadas para a situação problemática (SENGE, 2005; VALENÇA, 2011).

Em relação ao RU, figura 7, o arquétipo trata da gestão hierarquizada e centralizada deste, em que a qualidade e a precisão das ações tem sido deficientes, ocorrendo, na maioria das vezes, de maneira incompleta e insuficiente para solucionar os problemas. No primeiro momento as soluções urgentes e pontuais parecem corrigir a situação, com resultados aparentemente positivos, porém percebe-se posteriormente, que as ações devem ser revisadas para diminuir novamente a recorrência dos problemas. Com o tempo, a repetição desses procedimentos geram efeitos colaterais, como a percepção limitada do problema. Isso enseja a geração de informações sem qualidade e sem precisão, tornando as equipes acomodadas e despreocupadas na ação fundamental, sem contribuir com ações inovadoras. 
Figura 7 Arquétipo: transferência de responsabilidade

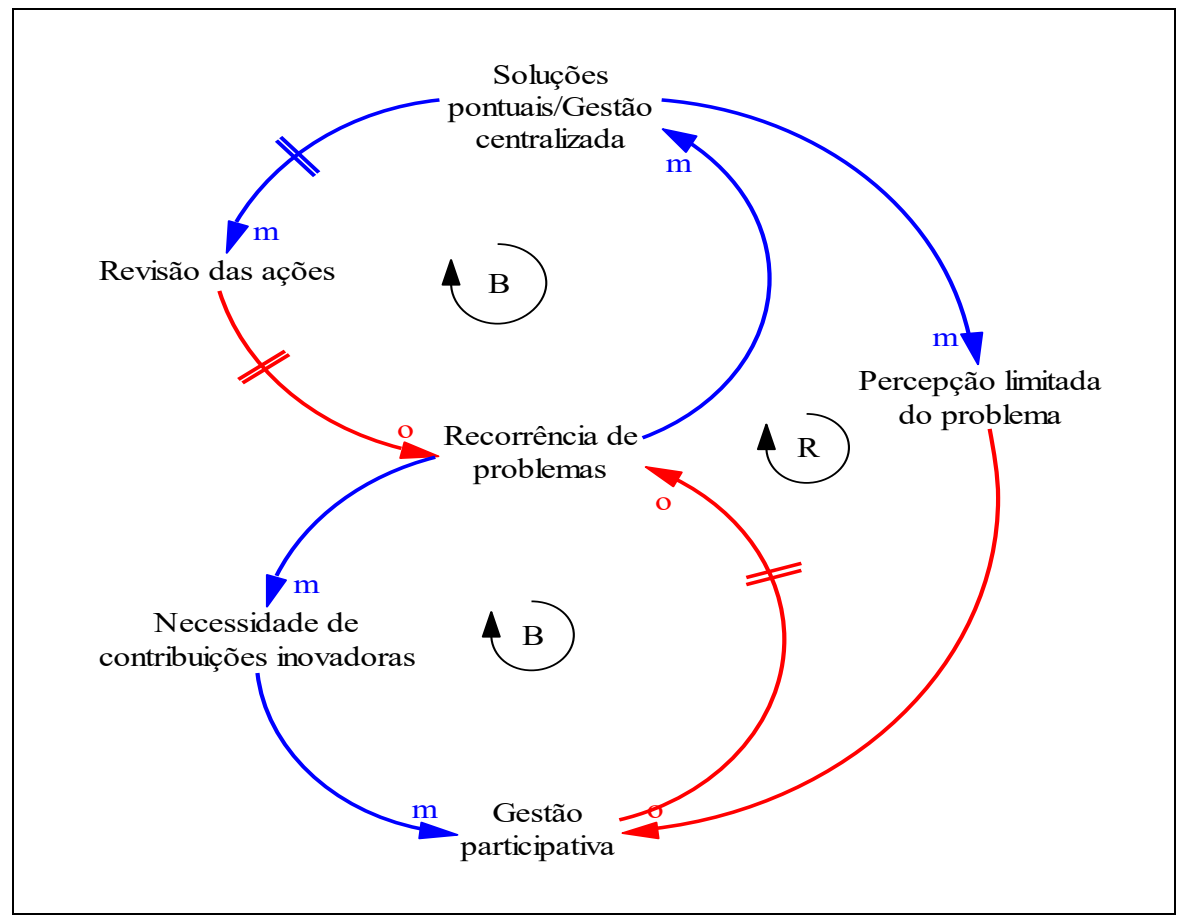

O ponto de alavancagem é fomentar a gestão participativa, elencando, por exemplo, comissões e inserindo a comunidade acadêmica e principalmente pessoas mais capacitadas nos processos decisórios. Porém vários fatores impedem a adoção imediata dessa solução. Um deles seria o desligamento progressivo do acompanhamento precário das ações e projetos em direção a um acompanhamento integrado, o que exige uma mudança de cultura e a assunção de responsabilidades dentro da instituição.

$\mathrm{Na}$ verdade, a estratégia mais eficiente para esta estrutura é aplicar imediatamente a solução rápida com o objetivo de solucionar o problema, mas, em paralelo, executar ações que levem à solução fundamental para garantir que o problema não torne a ocorrer.

\section{CONSIDERAÇÕES FINAIS}

Peter Senge, em sua obra, estabeleceu cinco disciplinas que levam ao aprendizado organizacional que estão diretamente ligadas a forma de pensar do indivíduo: domínio pessoal, modelos mentais, visão compartilhada, aprendizagem organizacional e o pensamento sistêmico. A quinta disciplina - pensamento sistêmico - surge em contraponto à ideia mecanicista operacionalizada por muitas organizações. Traz uma mudança de mentalidade em relação às realidades existentes no qual busca visualizar as inter-relações e o processo de mudança de forma holística. 
Essa visão do todo, vem trabalhar as limitações do raciocínio humano linear na busca do entendimento de que todos são responsáveis pelo sucesso ou insucesso de um sistema, tendo com isso, o mesmo poder de alavancagem para propor e implantar mudanças.

Diante desse contexto, percebeu-se a importância de desenvolver essa forma de pensamento dentro das organizações públicas para entender e agir de forma eficiente diante das situações, propiciando com isso um aprendizado contínuo e uma capacidade maior de criar e modificar contextos.

Ao trazer a realidade do restaurante universitário para a abordagem do pensamento sistêmico, foi possível perceber que, apesar da existência de algumas práticas gerenciais pontuais que buscam promover a aprendizagem, essas ações não refletem a lógica do pensamento holístico. São tratadas como ações paliativas, características de um pensamento linear onde não há o alcance das diversas dimensões que envolvem o problema central, ou seja, ora o problema é a fila, ora é a catraca e ora é o balcão (visão fragmentada).

São ações reativas e imediatistas focadas exclusivamente nos eventos, ao invés de atitudes adaptativas realizadas preventivamente, caracterizando, portanto, ausência de interrelação mútua. Isso, causa uma fragilidade no estudo dos fatores que interferem fortemente na dinâmica do RU que pode ser explicada por haver atuação diretamente sobre os efeitos em vez de uma atuação sobre os pontos de alavancagem que podem ser percebidos quando se tem a visão e análise do todo.

A análise das situações através dos arquétipos permitiu, não apenas, a estruturação sistêmica dos problemas, a análise racional e real da unidade, como também, a visualização das relações e o poder de influência de cada variável no sistema. Assim, as variáveis mais impactantes foram a capacidade de atendimento e o tamanho da fila que são os gargalos atuais da gestão. No método de análise foi visto que o desempenho do RU se elevará com a criação de novas unidades/ descentralização além da ampliação da unidade existente. Destaca-se, no entanto, a atividade de fornecimento de refeição como atividade-meio de gestão da instituição, sendo, portanto, passível de terceirização total dos serviços; e/ou a realização de convênios com a rede privada já existente no campus e no seu entorno mediante contratos com a instituição.

Outra sugestão é a criação de uma comissão multidisciplinar composta por representantes de todas as categorias interessadas (estudantes, gestores, servidores...) para atuar nos assuntos relativos à elaboração, monitoramento, avaliação e revisão de ações e/ou projetos de melhoria. 
Nessa perspectiva, uma análise estratégica aliada ao plano estratégico da instituição se faz necessária vislumbrando o cenário atual e futuro do RU para saber a viabilidade da adoção de um novo modelo de planejamento e gestão, através da implantação de um plano estratégico e um plano operacional, tendo em vista a complexidade das ações decorrentes da expansão do número de alunos e recursos financeiros limitados. Vale ressaltar que as decisões relacionadas aos restaurantes universitários possuem impactos econômicos e sociais, pois, além de envolver recursos elevados, também possuem uma função social, pois contribuem diretamente ou indiretamente para a qualidade de vida da sociedade no qual estão inseridos.

Espera-se que o estudo tenha contribuído para o início de uma mudança de mentalidade que busque analisar o todo dentro de um processo de mudança. Consequentemente, ter-se-á, uma gestão mais participativa capaz de atuar de forma preventiva e de propiciar um aprendizado contínuo em sua equipe em prol de resultados efetivos. Além de assegurar uma maior comunicação das decisões e compartilhamento das responsabilidades no processo decisório.

\section{REFERÊNCIAS}

ACCIOLY, Ruy Cordeiro; FIGUEIREDO, Reginaldo Santana. Análise do Complexo Agroindustrial Citrícola Utilizando Diagramas de Influência. Revista Produção Online, v. 1, n. $1,2010$.

BERTALANFFY, L. V. Teoria geral dos sistemas. 3ª ed. Petrópolis: Vozes, 1977.

CARVALHO, Guilherme Gonçalves de. Gestão de projetos na perspectiva do pensamento sistêmico e da teoria de ação (Dissertação). 254f. Recife, PE, 2010. Programa de PósGraduação em Ciência da Computação. Universidade Federal de Pernambuco.

DE SORDI, Jose Osvaldo; NELSON, Reed Elliot; BIANCHI, Eliane. Mapa Causal e o Ensino de Arquétipos Sistêmicos-DOI: http://dx. doi. org/10.15603/1982-8756/roc. v10n19p331-356. Revista Organizações em Contexto-online, v. 10, n. 19, p. 331-356, 2014.

FERREIRA, André Ribeiro. Modelo de excelência em gestão pública no governo brasileiro: importância e aplicação. In: XIV Congreso Internacional del CLAD sobre la Reforma del Estado y de la Administración Pública, Salvador, 27 - 30 out. 2009.

LEITE, M. S. A. Proposta de uma modelagem de referência para representar sistemas complexos. 2004. 420f. Tese (Doutorado) - Programa de Pós-Graduação em Engenharia de Produção, Universidade Federal de Santa Catarina, Florianópolis, 2004.

MAIA, T. M. L. Planejamento e Gestão Estratégica para o Restaurante Universitário da UFC em um cenário de expansão do número de alunos. (Dissertação) 106f. Fortaleza, CE, 
2008. Programa de Pós-Graduação em Políticas Públicas e Gestão da Educação Superior, Universidade Federal do Ceará.

MARQUES, C. S.; PEREIRA, B.A. D.; ALVES, J.N. Identificação dos principais fatores relacionados à infraestrutura universitária: uma análise em uma IES pública. Revista Sociais e Humanas, Santa Maria, v. 23, n. 01, jan/jun, p. 91-103, 2010.

MORIN, E. Ciência com consciência. 8. ed. Rio de Janeiro: Bertrand Brasil, 2005.

OLIVEIRA, Natacha Maria de Carvalho. Simulação a eventos discretos para a redução do tempo de espera em um restaurante (Dissertação). 126 f. Itajubá, MG, 2013.

Programa de Pós-graduação em Engenharia de Produção. Universidade Federal de Itajubá.

PRETO, S. C. S; FIGUEIREDO, L. F. G. de. O pensamento sistêmico como ferramenta organizacional da gestão de design nos grupos produtivos econômicos solidários. Projética Revista Científica de Design, Londrina,v.3, n.1, julho, 2012.

RICHE, Georges Ayoub; MONTE ALTO, Ricardo. As organizações que aprendem, segundo Peter Senge: "a quinta disciplina". Cadernos discentes COPPEAD, 36 Rio de Janeiro, n. 9, p. 36-55, 2001.

SENGE, Peter M. A quinta disciplina: arte, teoria e prática da organização de aprendizagem. 12. ed. São Paulo, SP: BestSeller, 1990.

, Peter M. A quinta disciplina: arte e prática da organização que aprende; Tradução: OP Traduções. Consultoria Zumble Aprendizagem Organizacional. 19a ed. Rio de Janeiro: BestSeller, 2005.

Peter M. A quinta disciplina: arte e prática da organização que aprende; Tradução: Gabriel Zide Neto. Rio de Janeiro: BestSeller, 2014.

SILVA, A. L.; LOURENZANI, A. E. B. S. Modelo sistêmico de ocorrência de ações coletivas: um estudo multicaso na comercialização de frutas, legumes e verduras. Gest. Prod., São Carlos, v. 18, n. 1, p. 159-174, 2011. Disponível em:

http://www.scielo.br/scielo.php?script=sci_arttext\&pid=S0104-530X2011000100012. Acesso em: 23 ago 2015.

SILVA. Reinaldo O. da. Teorias da Administração. São Paulo: Pearson Prentice Hall, 2008. SORDI, J. O.; NELSON, R. E.; BIANCHI, E. Mapa causal e o ensino de arquétipos sistêmicos. Revista Organizações em Contexto, v. 10, n. 19, p. 331-356, 2014. Disponível em: https://www.metodista.br/revistas/revistas-ims/index.php/OC/article/view/4660/pdf_96. Acesso em: 20 ago 2015.

UNIVERSIDADE FEDERAL DE PERNAMBUCO. Pró-Reitoria de Assuntos Estudantis. Restaurante Universitário. Pesquisas de opinião 2011- 2014. Recife, 2015.

VALENÇA, Antonio Carlos (org.). Aprendizagem organizacional: 123 aplicações práticas de arquétipos sistêmicos. São Paulo: Senac, 2011. 
VILLELA, P. R. C. Introdução à dinâmica de sistemas. UFJF. 2005. Disponível em: www.ufjf.br/ciro_barbosa/files/2011/02/ds_parte1.pdf. Acesso em: 23 ago 2015.

WOLSTENHOLME, E. F. Towards the definition and use of a core set of archetypal structures in system dynamics. System Dynamics Review, v. 19, n. 1, p.7-26, 2003. 